\title{
SEPARATING HYDROGEN FROM COAL GASIFICATION GASES WITH ALUMINA MEMBRANES*
}

\author{
B. Z. Egan \\ CONF-910601--1 \\ Chemical Technology Division \\ Oak Ridge National Laboratory \\ DE91 004540 \\ Oak Ridge, TN 37831
}

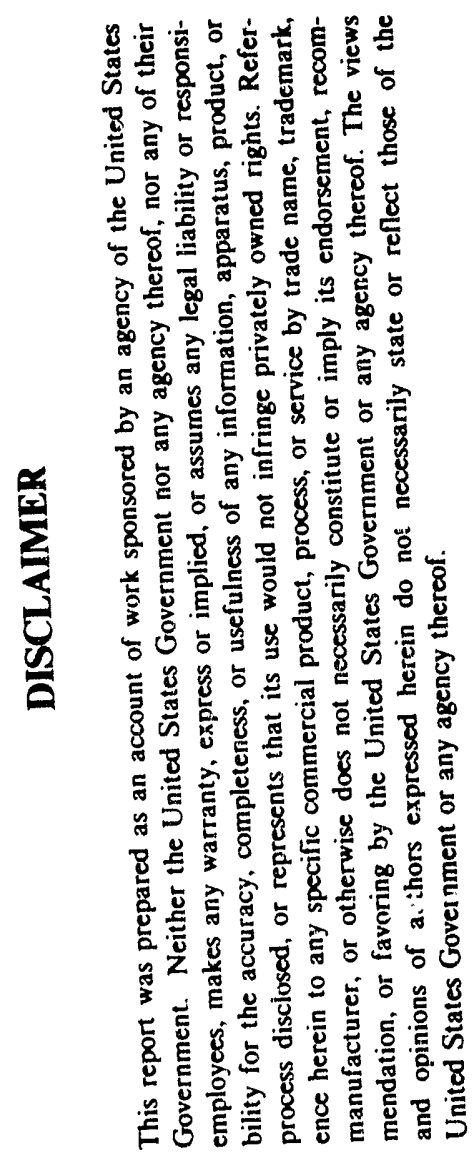

\author{
D. E. Fain \\ G. E. Roettger \\ D. E. White \\ Technical Division \\ Oak Ridge K-25 Site \\ Oak Ridge, TN 37831
}

To be presented at the 36th International Gas Turbine and Acroengine Congress and Exposition Orlando, Florida June 3-6, 1991

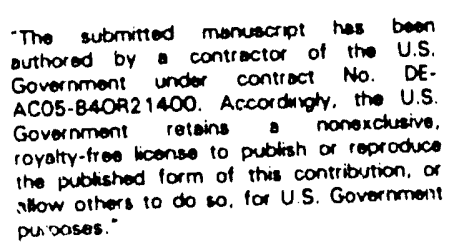

-Research sponsored by U.S. Department of Energy, AR\&TD Fossil Energy Materials Program, and the Morgantown Energy Technology Center, under contract DE-ACO5-84OR21400 with Martin Marictta Energy Systems, Inc. 


\title{
SEPARATING HYDROGEN FROM COAL GASIFICATION GASES \\ WITH ALUMINA MEMBRANES
}

\author{
B. Z. Egan, D. E. Fain, G. E Rocttger, D. E. White
}

\begin{abstract}
Synthesis gas produced in coal gasification processes contains hydrogen, along with carbon monoxide, carbon dioxide, hydrogen sulfide, water, nitrogen, and other gases, depending on the particular gasification process. Development of membrane technology to separate the hydrogen from the raw gas at the high operating temperatures and pressures near exit gas conditions would improve the efficiency of the process.

Tubular porous alumina membranes with mean pore radii ranging from about 9 to $22 \mathrm{~A}$ have been fabricated and characterized. Based on hydrostatic tests, the burst strength of the membranes ranged from 800 to $1600 \mathrm{psig}$, with a mean value of about 1300 psig. These membranes were evaluated for separating hydrogen and other gases.

Tests of membrane permeabilities were made with helium, nitrogen, and carbon dioxide. Measurements were made at room temperature in the pressure range of 15 to $589 \mathrm{psi}$. Selected membranes were tested further with mixed gases simulating a coal gasification product gas. In general, the relative gas permeabilitics correlated qualitatively with a Knudsen flow mechanism. However, other gas transport mechanisms such as surface adsorption may also be involved.

Efforts are underway to fabricate membranes having still smaller pores. At smaller pore sizes, higher separation factors are expected from molecular sieving effects.
\end{abstract}




\section{INTRODUCTION}

Synthesis gas produced in coal gasilication processes may contain hydrogen, carton monoxide, nitrogen, water, carbon dioxide, hydrogen sulfide, and other gases, depeuding on the particular gasification process. The hydrogen and carbon monoxide in the synthesis gas has significart value. Hydrogen is an important and valuable raw material that has numerous uses in the chemical and fuel industries. If membrane technology could be developed to separate these gases undar gasifier exit gas conditions, it would significantly improve process efficiency and economics, and simultaneously provide for the recovery of valuable gases. Inorganic membranes could potentially be used for this purpose.

The purpose of this ongoing R\&D program is to develop, fabricate, and test inorganic membrane systems for the separation and recovery of coal gasification gases, particularly hydrogen. Major aspects of the program include (1) identification and selection of candidate membrane materials; (2) fabrication and physical characterization of candidate membranes using specialized techniques available at the Oak Ridge K-25 Site; and (3) evaluation of the separations capability of the fabricated membranes in terms of permeabilities and fluxes of gases.

Until recently, inorganic membranes have been used primarily for microfiltration and ultrafiltration. While polymeric membranes have been used on a commercial scale to separate various gases, such as hydrogen and ammonia, oxygen and nitrogen, and carbon dioxide and methane, there has been no large-scale application of porous inorganic membrane separations to gases except for uranium enrichment. Polymeric membranes have limited stability and are susceptible to abrasion and chemical attack. Consequently, they cannot be used in separation processes at high temperatures and pressures. Porous metal, glass, and ecramic membranes are stable to much higher temperatures than polymeric membranes, and the limitation is usually set by the suals and module materials rather than the membrane itself. 
Several porous inorganic materials that could be used as membranes are commercially available (1), but the minimum pore diameter is in the range of 30 to $40 \AA$. While some gas separations can be achieved with these materials, it is generally accepted that smaller pore diameters or other membrane modifications will be needed for efficient gas separations.

Commercially, at present, bulk removal of acid gases from raw process gas such as synthesis gas is carried out by using solvent scrubbing processes such as methyldiethanolamine (MDEA), Selexol, and Rectisol. Most of these solvent scrubbing processes operate at temperatures below $200^{\circ} \mathrm{F}$. Figure $1 \mathrm{a}$ is a simpified block flow diagram of a typical entrained-bed coal gasificationcombined cycle (IGCC) process. Present technology requires cooling the product gases from $1500^{\circ} \mathrm{F}$ to $100^{\circ} \mathrm{F}$ to permit removal of $\mathrm{CO}_{2}, \mathrm{H}_{2} \mathrm{~S}$, and other contaminant gases. The cleaned fuel gas $(\mathrm{CO}$ $\mathrm{H}_{2}$ ) must then be reheated to $500-600^{\circ} \mathrm{F}$ for dowr stream combustion in a gas turbine to generate power. The efficiency of the process could be increased substantially if the contaminant gases could be separated at the higher downstream operating temperature. The proposed membrane separation process (2) would be developed to operate at conditions closer to the exit gas conditions than presently known processes. A block flow diagram for a conceptual membrane gas separation system for this application is shown in Figure 1b. Briefly stated, the gas cooling and the gas cleanup system would be replaced by a membrane separation system operating at high temperature.

The performance targets for the membrane separation process were determined, based on the coal gasification process operating temperatures and pressures and gas flux requirements. Potential membrane materials were selected, based on thermal and chemical stability, availability and cost of raw materials, and effects on gas transport mechanisms. The technical approach was to develop and fabricate membranes with small pores (less than $20 \AA$ ) and a narrow pore size distribution. For safety reasons, helium was used to simulate the behavior of hydrogen. Eventually, the best membranes will be tested with a coal gasification mixture containing hydrogen. 

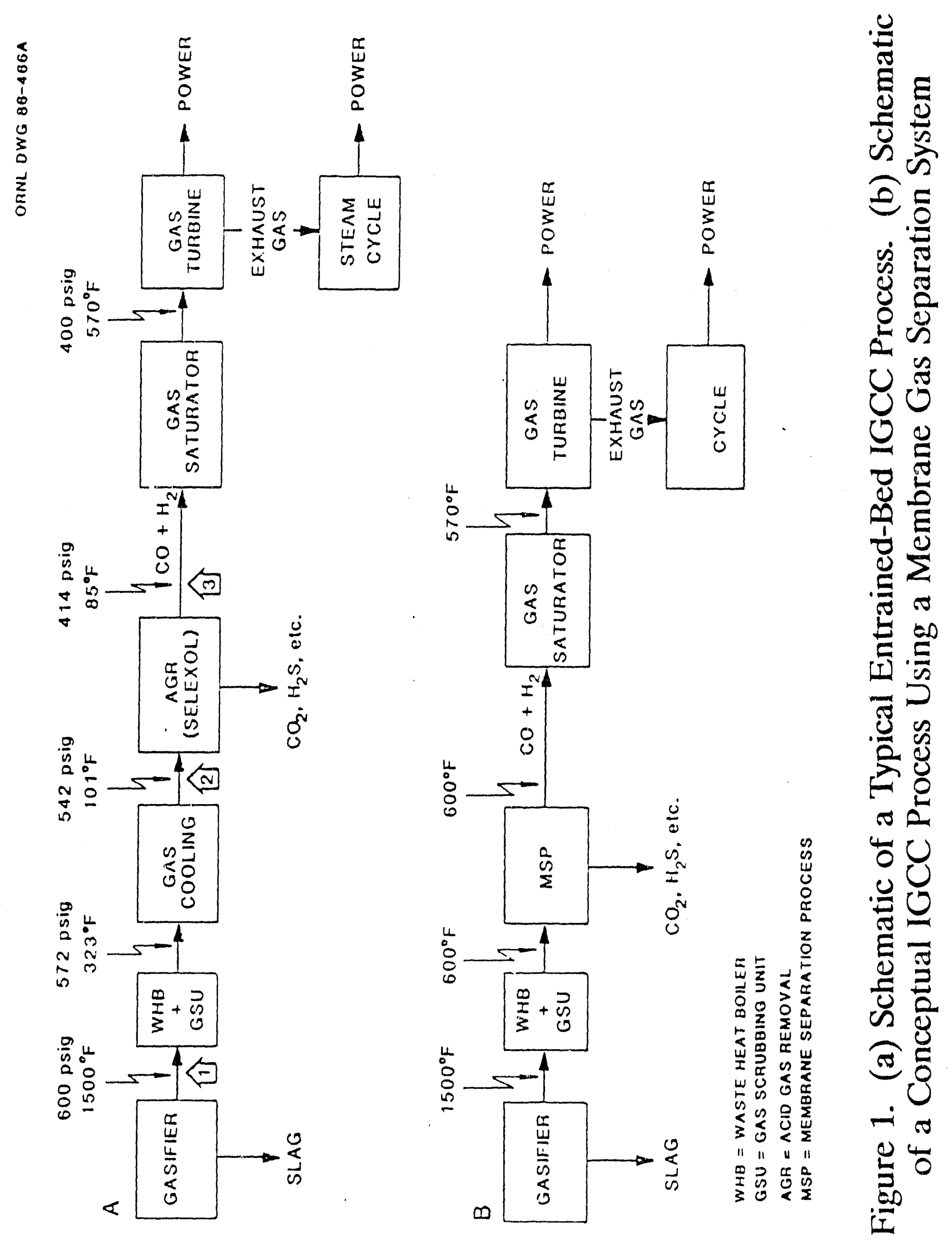


\section{RESULTS AND DISCUSSION}

\section{Selection of Membrane Materials}

Metallic membranes have been used in a few cases for scparating hydrogen from other gases, but most applications of metallic membranes have heen directed toward separating hydrogen, deuterium, and tritium isotopes. One application is the removal of tritium from radioactive eflluent from nuclear fuel reprocessing plants; another is separation of the hydrogen isotopes produced in a fusion reactor. The most common metallic membrane is palladium, usually alloyed with silver to improve the physical and mechanical properties of the membrane.

The separation of several gases with porous glass membranes has been demonstrated. Some of the gases that have been separated using porous glass membranes include hydrogen, helium, argon, nitrogen, oxygen, carbon dioxide, carbon monoxide, and light hydrocarbons. Disadvantages of porous glass include limited thermal properties and relatively low gas permeabilities.

The most frequently used materials for metallic oxide membranes are alumina and silica. Some membranes contain mixtures of these along with other oxides such as zirconia or titania. Alumina is also frequently used as the support for other membrane materials. Membranes with pore sizes ranging from a few angstroms to nearly a micrometer have been prepared. The permeation behavior of several gases has been studied using alumina or alumina-containing membranes. These gases include hydrogen, nitrogen, helium, argon, oxygen, carbon dioxide, sulfur dioxide, hydrogen sulfide, water, alcohols, and light hydrocarbons. Alumina membranes with a variety of pore sizes and configurations are available commercially.

Alumina was selected as the best membrane material for our initial studies for separating coal gasification gases. A variety of low-cost alumina starting materials are readily available. Alumina has relatively low chemical reactivity, good thermal properties, and is readily adaptable to fabrication methods. 


\section{Membrane Fabrication and Charactcrization}

Over 100 tubular alumina membranes, having a diameter of about $0.9 \mathrm{~cm}$ and a wall thickness less than $1 \mathrm{~mm}$, have been fabricated. The pore size distributions of several experimental alumina membranes were measured using a dynamic pore size measurement technique ( $\underline{3})$. An example of the pore size distribution of an experimental membrane is shown in Figure 2. The mean pore radius of the membranes has been reduced to less than $10 \AA$, with essentially no pores with a radius larger than $20 \AA$.

Hydrostatic tests were made on six of the tubular membranes to determine their burst strength at room temperature (4). The burst strength at $1000^{\circ} \mathrm{F}$ is expected to be about $90 \%$ of the value determined at room temperature. The burst strength values ranged from 800 to $1600 \mathrm{psig}$, with a mean value of about 1300 psig.

\section{Membrane Test System}

A test apparatus for measuring the gas permeabilities of membranes at high temperatures (up to $500^{\circ} \mathrm{C}$ ) and pressures (up to $4 \mathrm{MPa}$ ) was designed and constructed (). A flow diagram of the apparatus is shown in Figure 3. Gases are supplied from cylinders through high-pressure regulators and an associated manifold. Pressures are controlled by pressure control valves, and gas flows are measured with differential pressure transmitters. The gases are preheated in a tubular furnace, which also houses the membrane enclosed in an outer tube. Temperatures are measured with thermocouples. Exit gases are cooled with heat exchangers if necessary, and analyzed by gas chromatography. Shutoff valves are operated by air-controlled actuators, supplied through solenoidoperated valves. The recorder/controllers, thermocouple readouts, and valve switches are installed in a separate instrument cabinet. For safety reasons, the system is enclosed in a free-standing fume hood. 


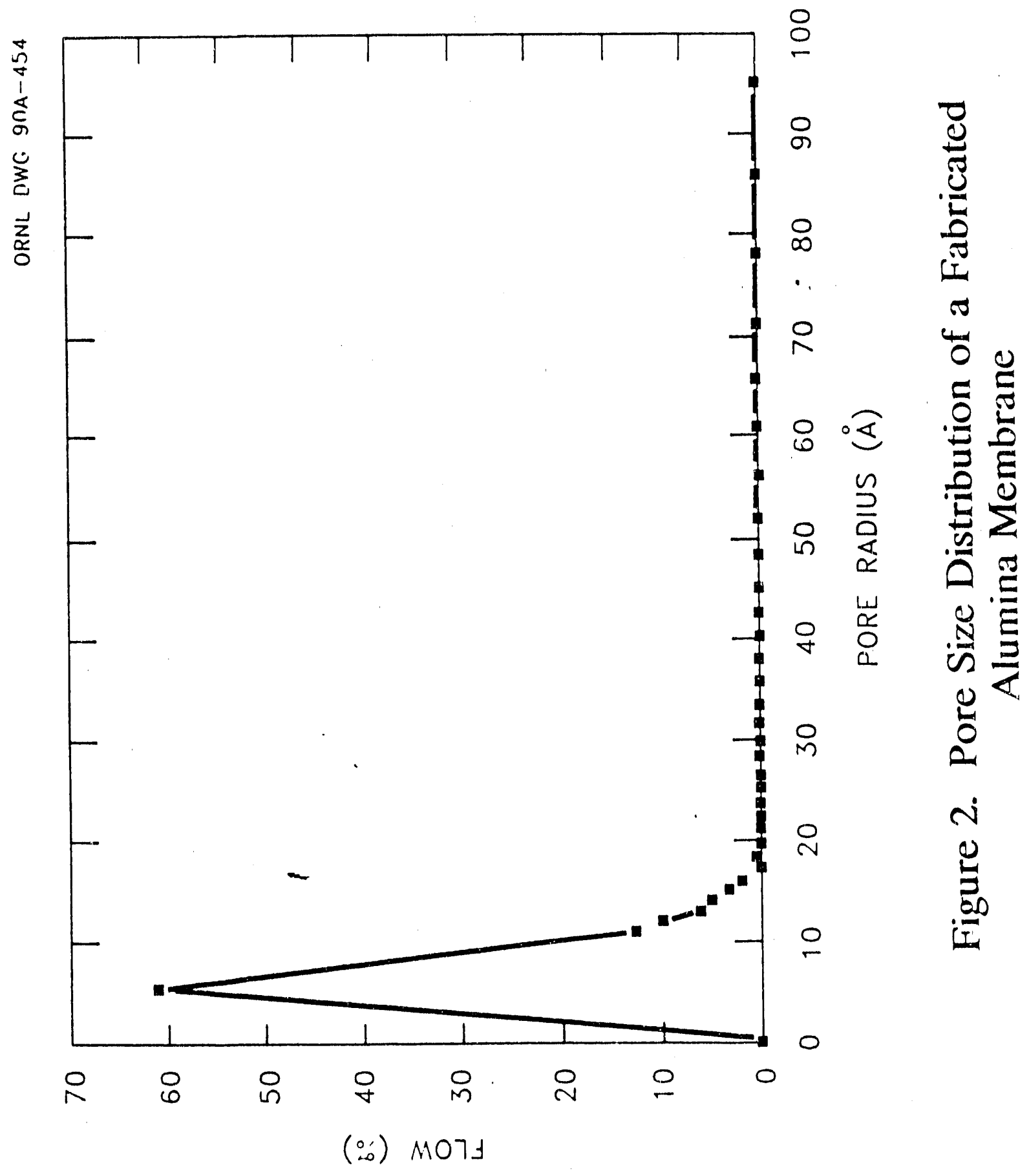




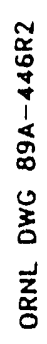

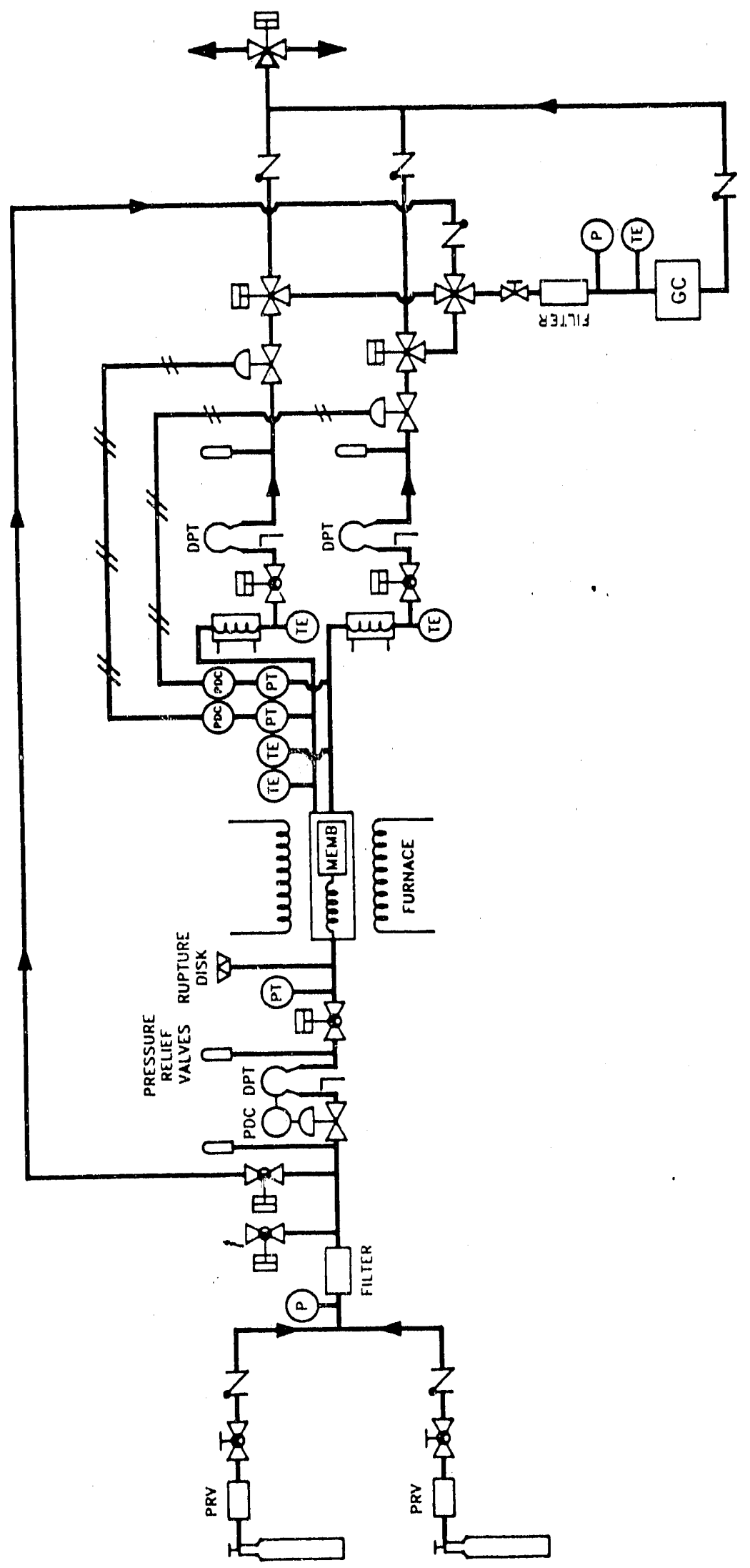

है

疍

옹

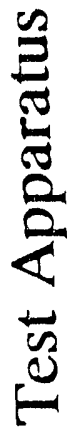

m

$\Xi_{0}^{0}$ 
Gas Pcrmeability Measurcments (ㅁ)

Several alumina membranes, having different pore radii ranging from about 7 to $18 \AA$, were fabricated. The permeabilities of the membranes were measured at room temperature in different pressure ranges using helium, nitrogen, and carbon dioxide. Typical results for one of the membranes are shown in Figure 4, in which the "permeability versus pressure summation" is plotted. The pressure summation values are the sums of the feed and permeate pressure. The permeability of the gases did not vary appreciably with pressure for the gases in the pressure range shown. Permeability measurements were also made at higher pressures using the test apparatus described in Figure 3. These measurements were made at room temperature in the feed gas pressure range of 15 to 150 psi (Figure 5). Nitrogen and helium permeabilities of another membrane sample were measured up to a feed gas pressure of 589 psi (Figure 6).

The data for the low pressure measurements are summarized in Figure 7, in which the calculated separation factors (ratio of pure gas permeabilities) for helium/nitrogen and helium/carbon dioxide are plotted versus the average pore size for seven different alumina membranes. Also shown in Figure 7 are the calculated ideal separation factors, assuming a Knudsen gas transport mechanism. Knudsen or free-molecule diffusion occurs when the pore is much smaller than the mean free path of the gas molecules, and the gas flux can be described by the expression:

$$
\begin{aligned}
& \mathrm{G}=\frac{8 \mathrm{r}\left(\mathrm{P}_{1}-\mathrm{P}_{2}\right)}{3 \mathrm{~L}(2 \pi \mathrm{MRT})^{1 / 2}} \\
& \mathrm{G}=\text { molecular flow } \\
& \mathrm{r}=\text { pore radius } \\
& \mathrm{P}_{1}=\text { partial pressure of gas on feed side } \\
& \mathrm{P}_{2}=\text { partial pressure of gas on permeate side } \\
& \mathrm{L}=\text { pore length } \\
& \mathrm{M}=\text { molecular weight } \\
& \mathrm{R}=\text { gas constant } \\
& \mathrm{T}=\text { absolute temperature }
\end{aligned}
$$




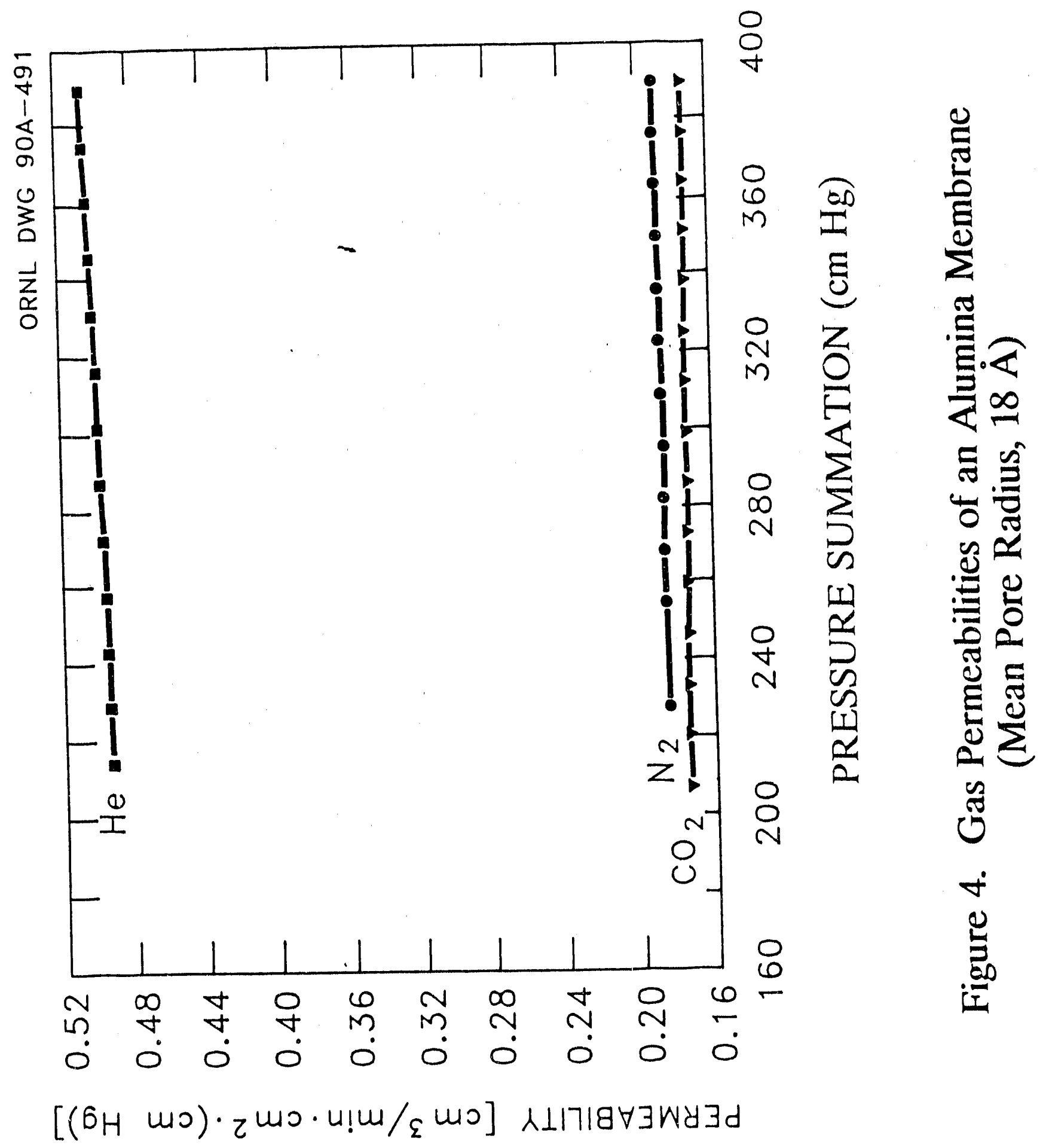



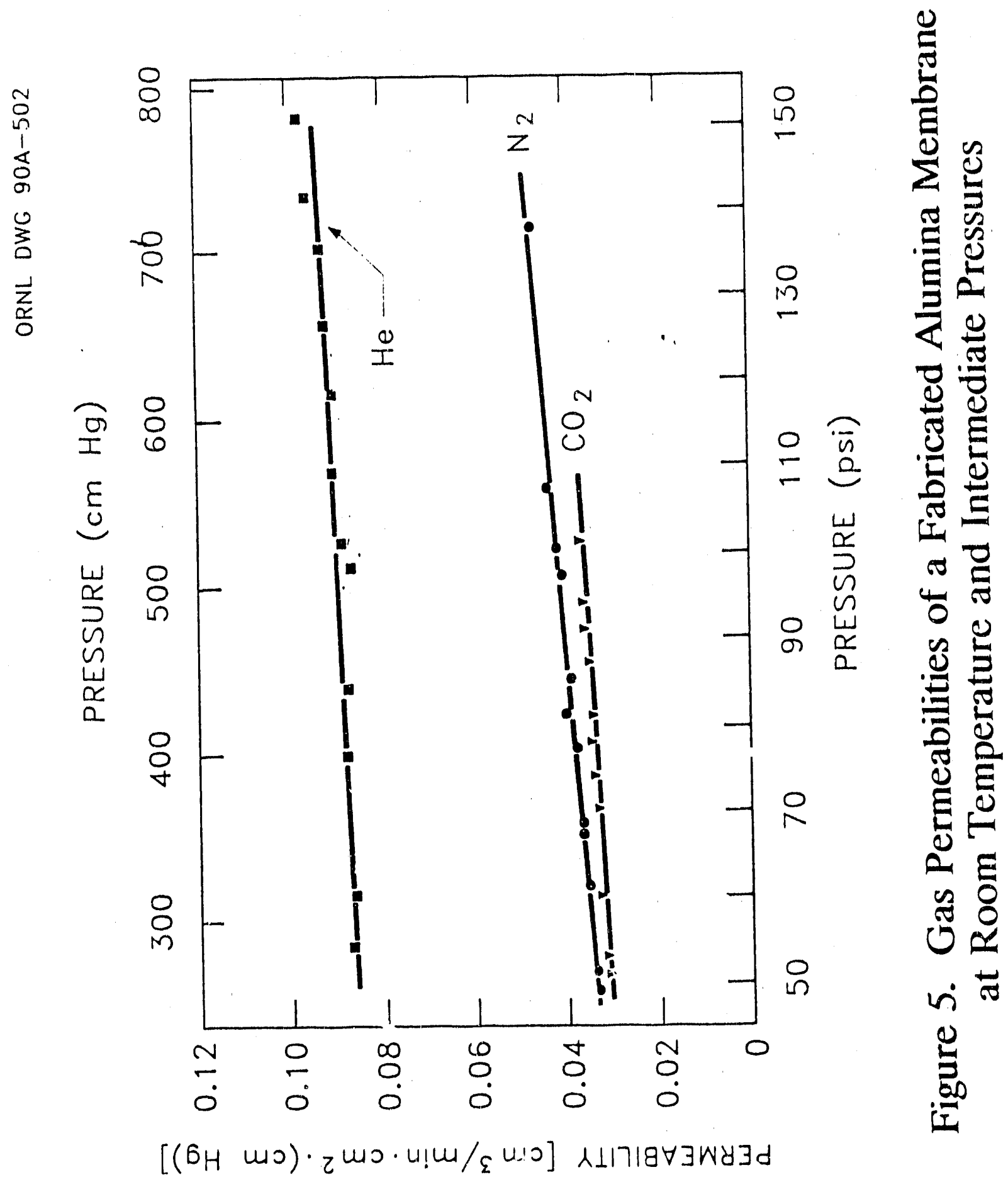


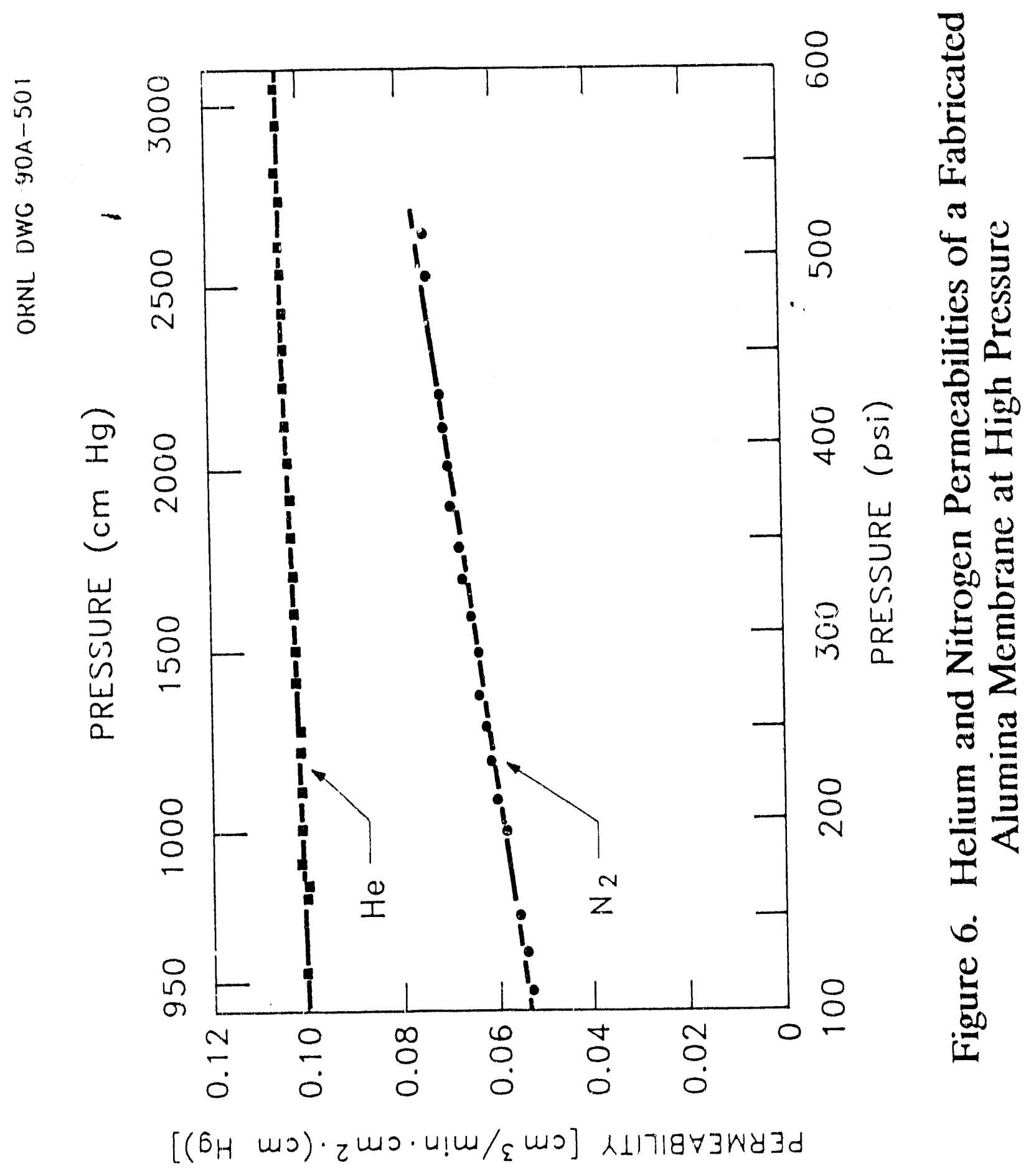




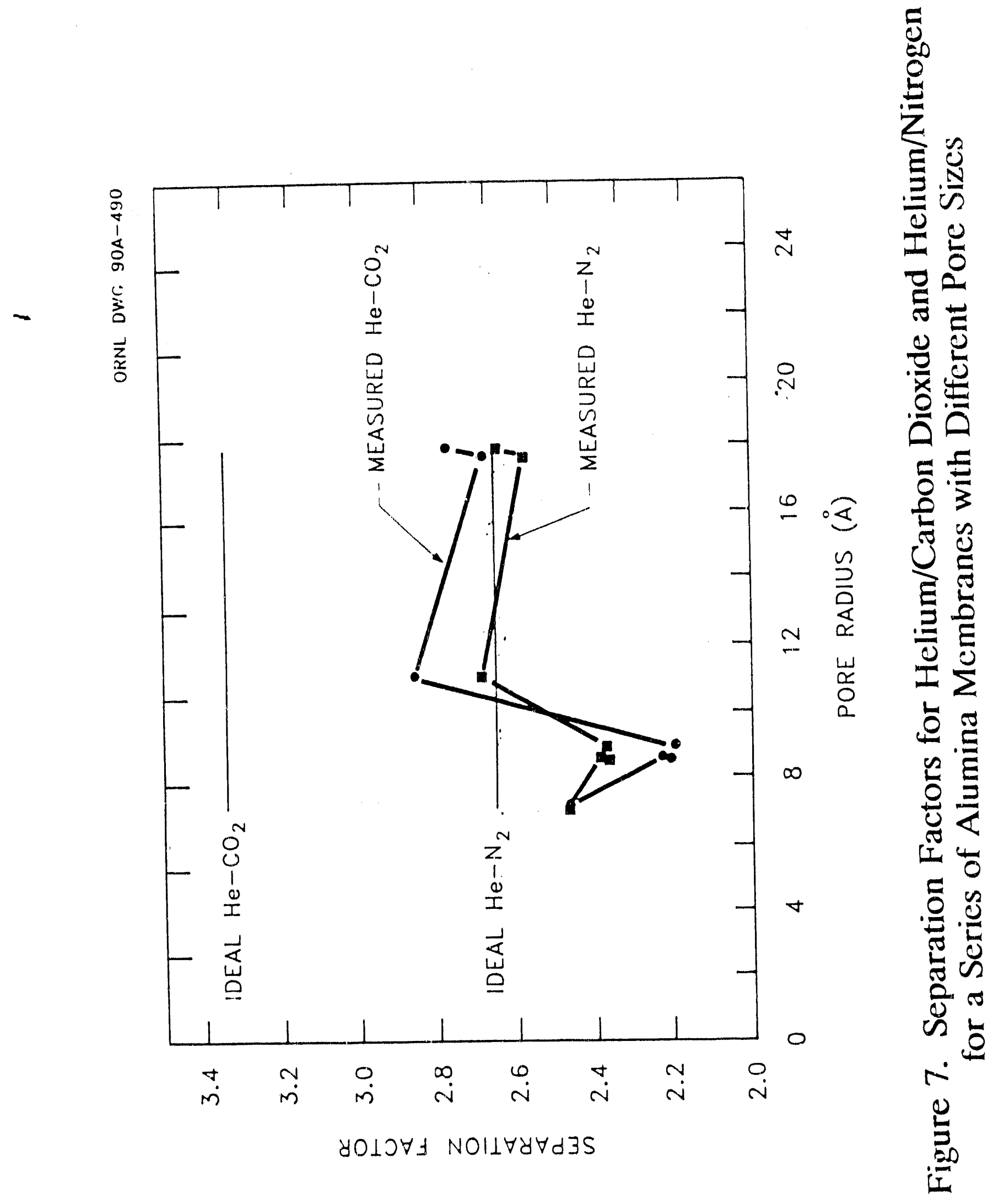


For Knudsen flow, the separation factor for binary gas mixtures can be estimated from the square root of the ratio of the molecular weights. The smaller molecules with a higher velocity move through the pores faster. These are ideal separation factors. Actual separation factors also depend on the molar composition (mol fraction) of the gases in the feed and permeate.

In general, the relative gas permeabilities of the fabricated membranes correlate qualitatively with a Knudsen flow mechanism. However, it is apparent that other gas transport mechanisms play a role. The enhanced permeability of carbon dioxide, probably due to surface adsorption or other membrane interaction, reduces the helium/carbon dioxide separation factor. The helium/ritrogen separation factor is also reduced somewhat as the membrane pore size decreases (Figure 7) and as the pressure increases (Figure 6).

It is projected that as membranes are developed which have pore sizes comparable to the size of gas molecules, some molecular screening can occur (프). Larger separation factors should then be achievable. In practice, there will be a distribution of pore sizes, and the gas permeabilities can best be described by a combination of transport mechanisms.

Efforts are being made to produce membranes with a mean pore radius below $5 \AA$. Other efforts are directed toward developing better alumina-metal seals so that gas permeability measurements can be made at higher temperatures.

\section{ACKNOWLEDGMENTS}

Excellent technical assistance was provided by Dale Adcock and Betty Evans. The manuscript was prepared by Janet Brown. This research was sponsored by the U.S. Department of Energy, Morgantown Energy Technology Center, and the AR\&TD Fossil Energy Matcrials Program, under contract DE-AC05-84OR21400 with Martin Marictta Encrgy Systems, Inc. 


\section{REFERENCES}

(1) Egan, B. Z., 1989, "Using Inorganic Membranes to Separate Gases: R\&D Status Review," ORNL/TM-11345, Oak Ridge National Laboratory, Oak Ridge, TN.

(2) Egan, B. Z., Fain, D. E., Kidd, G. J., and Singh, S. P. N., 1988, "Gas Separations Using Inorganic Membranes," Proceedings of the Eighth Annual Gasification and Gas Stream Cleanup Systems Contractors Review Meeting, V. P. Kothari and J. R. Longanbach, eds., Morrantown Energy technology Center, Morgantown, WV, Vol. II, pp. 519-524.

(3) Fain, D. E. and Roettger, G. E., 1990, "Developrnent of Ceramic Membranes for Gas Separation," Proceedings of the Fourth Annual Conference on Fossil Ener sy Materials, ORNL/FMP-90/1, R. R. Judkins and D. N. Braski, compilers, Oak Ridge National Laboratory, Oak Ridge, TN., pp. 183-194.

(4) Fain, D. E., Kidd, Jr, G. J., Roettger, G. E., and White, D. E., 1990, "Development of Ceramic Membranes for Gas Separation - FY 1989 Development Activities," K/QT-352, Oak Ridge Gaseous Diffusion Plant, Oak Ridge, TN.

(5) Egan, B. Z., Fain, D. E., Roettger, G. E., Singh, S. P. N., and White, D. E., "Gas Separations Using Inorganic Membranes," Presented at the Tenth Annual Gasification and Gas Stream Cleanup Systems Contractors Review' Meeting, Morgantown, WV, August 28-30, 1990. 

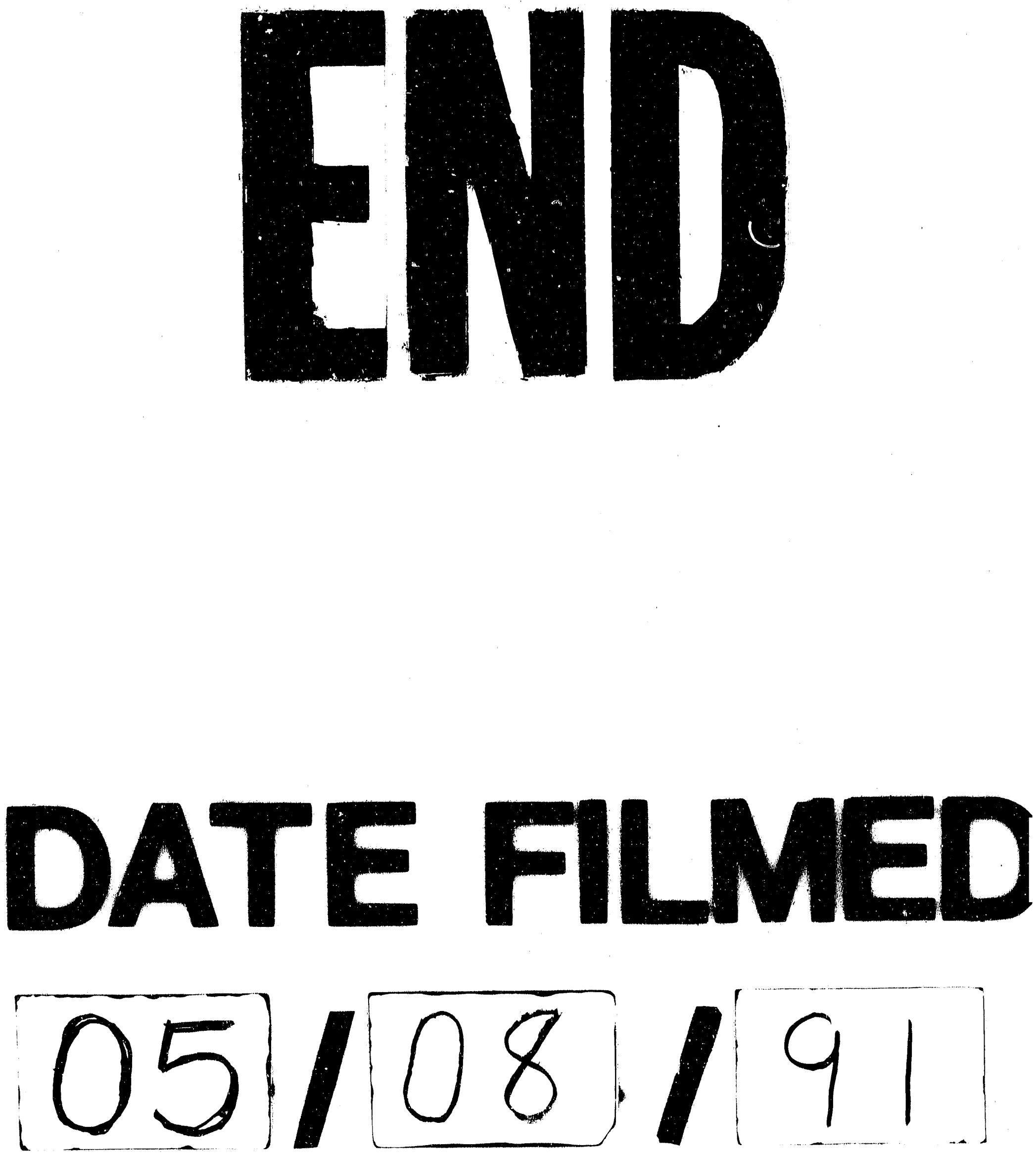
